\title{
铑催化的烯烃不对称氢甲酰化反应研究进展
}

\author{
贾肖飞 $a, b \quad$ 王 正 ${ }^{b}$ 夏春谷 ${ }^{a} \quad$ 丁奎岭 $*, b$ \\ ( ${ }^{a}$ 羰基合成与选择性氧化国家重点实验室 中国科学院兰州化学物理研究所 兰州 730000) \\ ( ${ }^{b}$ 金属有机化学国家重点实验室 中国科学院上海有机化学研究所 上海 200032)
}

\begin{abstract}
摘要 烯烃的氢甲酰化反应是工业上最重要的均相催化反应之一，而通过烯烃的不对称氢甲酰化反应合成光学活性 醛，对于药物、农药、香料和天然产物合成方面具有重要的意义. 近年来，由于铑与膦配体形成的络合物在催化烯烃的 不对称氢甲酰化反应中具有反应活性高、选择性好等优点而引起广泛关注. 通过调控铑络合物中手性膦配体的电子与 立体化学环境, 已经成为实现不对称氢甲酰化反应高活性和高选择性最主要的方法. 主要介绍了近期在铑催化的不对 称氢甲酰化反应研究方面取得的进展, 重点介绍几类代表性的手性膦配体在此类反应中的应用.
\end{abstract}

关键词 醛; 不对称催化; 手性膦配体; 氢甲酰化; 烯烃; 铑

\section{Recent Advances in Rh-Catalyzed Asymmetric Hydroformylation of Olefins}

\author{
Jia, Xiaofei ${ }^{a, b} \quad$ Wang, Zheng $^{b} \quad$ Xia, Chungu $^{a} \quad$ Ding, Kuiling ${ }^{*, b}$ \\ ( ${ }^{a}$ State Key Laboratory of Oxo Synthesis and Selective Oxidation, Lanzhou Institute of Chemical Physics, \\ Chinese Academy of Sciences, Lanzhou 730000) \\ $\left({ }^{b}\right.$ State Key Laboratory of Organometallic Chemistry, Shanghai Institute of Organic Chemistry, \\ Chinese Academy of Sciences, Shanghai 200032)
}

\begin{abstract}
Hydroformylation is one of the most important processes of homogeneous catalysis in industry. Asymmetric hydroformylation (AHF) of prochiral alkenes provides an efficient way to the synthesis of optically active aldehydes, which are versatile chiral intermediates for pharmaceuticals, agrochemicals, and other fine chemicals. So far, most of methods reported were focused on the use of $\mathrm{Rh}(\mathrm{I})$-based catalysts, by virtue of their high catalytic activity and excellent chemoselectivity for the aldehydes. A key issue in searching for efficient asymmetric hydroformylation catalysts is the development of new chiral ligands. A number of chiral phosphorus ligands have been successfully developed for Rh(I)-catalyzed AHF reactions. In this review, the recent advances in the development of chiral ligands for the Rh-catalyzed asymmetric hydroformylaion of olefins have been surveyed.
\end{abstract}

Keywords aldehyde; asymmetric catalysis; chiral phosphine ligand; hydroformylation; olefin, rhodium

氢甲酰化反应是指烯烃与 $\mathrm{CO}$ 和 $\mathrm{H}_{2}$ 在催化剂的作 用下生成醛的反应, 最早由 Roelen 在 1938 发现 ${ }^{[1]}$. 由于 醛可以方便地进一步转化为成醇、酸、酯、Aldol 缩合 产物、缩醉等化学品, 而这些化学品是生成各种洗涤剂、 表面活性剂或医药和香料等高附加值精细化学品的主 要原料, 所以氢甲酰化已发展成为迄今最重要的工业均 相催化反应之一. 据统计, 全球通过氢甲酰化生产醛、 醇的能力在 2008 年已经达到千万吨规模 ${ }^{[2]}$.

烯烃在手性催化剂的作用下与 $\mathrm{CO} / \mathrm{H}_{2}$ 反应, 生成光
学活性醛的反应称为不对称氢甲酰化反应 ${ }^{[3]}$. 如 Scheme 1 所示，根据烯烃或其取代基种类的不同，通过该反应 可以方便地制备多种类型的光学活性醛. 如从单取代烯 烃可得到支链的手性醛(Scheme 1a); 对于 1,2-双取代烯 烃, 由于区域选择性的不同可得到两个手性醛(Scheme $1 b$ ); 当底物为 1,1-双取代烯烃时，由于取代基立体位阻 的影响, 产物通常以直链醛为主, 含手性季碳的醛较少 (Scheme 1c); 三取代烯烃经不对称氢甲酰化反应，则可 得到含有两个手性中心的醛和手性季碳的醛(Scheme

\footnotetext{
*E-mail: cgxia@1zb.ac.cn, kding@mail.sioc.ac.cn

Received April 6, 2013; revised April 22, 2013; published online April 24, 2013

Project supported by the National Natural Science Foundation of China (Nos. 21172237, 21121062, 21032009).

国家自然科学基金(Nos. 21172237, 21121062, 21032009)资助项目.
} 
1d). 至今, 相关的研究工作主要集中于单取代烯烃和 1,2-双取代烯烃的不对称氢甲酰化反应，而 1,1-双取代 烯烃和三取代烯烃的相关研究工作较少. 这些手性醛通 常是重要的有机合成中间体，可通过氢化、氧化、Aldol、 还原胺化等反应进一步转化为醛的各种衍生物, 如光学 活性的醇、酸、酯、胺等, 在制药、农药、香料、和天 然产物合成等领域具有广泛的应用 ${ }^{[4]}$.

(a)<smiles>[R]C=CC(=O)O</smiles>

(b)

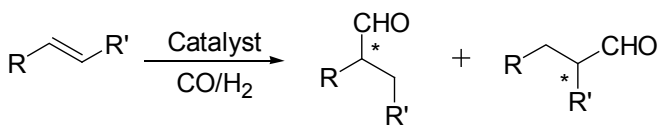

(c)

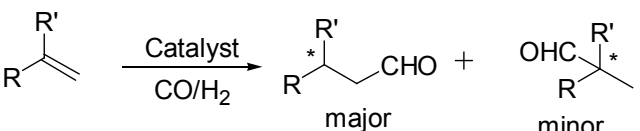

(d)

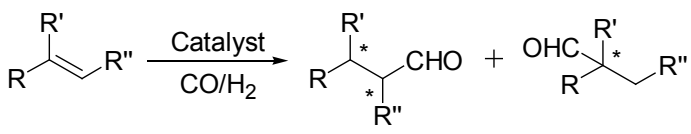

Scheme 1

虽然早在 20 世纪 70 年代, 科学家就已经开始了不 对称氢甲酰化反应的研究, 但至今还没有在工业中获得 实际应用的例子. 其中一个重要原因在于, 该反应需要 同时有效地控制化学选择性(氢甲酰化、氢化和异构化)、 区域选择性(支链醛/直链醛, $b: l$ ) 和对映选择性( $e e$ 值). 以 Scheme 2 所示的单取代烯烃的不对称氢甲酰化为例, 在反应条件下烯烃可能同时会发生不同程度的氢化和/ 或异构化，因而产生化学选择性的问题; 氢甲酰化反应 中醛基 $(\mathrm{CHO})$ 可能加在 $\mathrm{C}=\mathrm{C}$ 双键的两个不同位置上, 从而得到支链醛或直链醛，所以有区域选择性控制问 题; 对于形成新手性中心的支链醛, 由于醛基加在烯烃 $\mathrm{C}=\mathrm{C}$ 双键的两个不同的面上, 可以得到两种不同构型 的手性醛，因此还有对映选择性问题. 另一方面，为了 使铑一膦催化剂有较高的反应活性，不对称氢甲酰化反 应的温度一般比较高 $\left(60 \sim 100{ }^{\circ} \mathrm{C}\right)$, 这在一定程度上也 使得反应的各种选择性控制更加困难; 同时, 如果在醛 羰基的 $\alpha$ 位含有一个活泼氢，在较高的反应温度下，所 得到的光学活性醛还可能发生消旋化. 所有上述因素, 都决定了烯烃的不对称氢甲酰化是一类十分具有挑战 性的不对称催化过程.

最早的不对称氢甲酰化报道出现在 1972 年, 采用 手性席夫碱修饰的钴络合物 ${ }^{[5]}$ 或手性单膦配体修饰的铑 络合物为催化剂 ${ }^{[6]}$. 其中钴催化的苯乙烯的不对称氢甲 酰化反应选择性较差, 副反应烯烃氢化产物收率超过

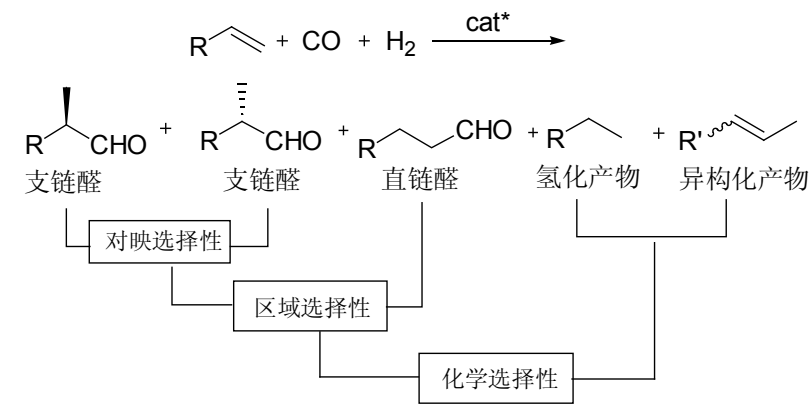

Scheme 2

$52 \%$, 且支链醛的选择性较低( $b: l=59: 41)$, 对映选择 性也仅为 $3 \%$ ee. 最早的铑催化剂使用一类手性单膦配 体修饰，在苯乙烯的不对称氢甲酰化反应中，虽然可以 取得较好的化学和区域选择性 $(b: l=90: 10)$, 但是反 应的对映选择性仍然很低 $(18 \% e e) .1973$ 年, Pino 等 ${ }^{[7]}$ 第 一次将手性双膦配体应用于铑催化的不对称氢甲酰化 反应中，他们将 $\mathrm{RhH}(\mathrm{CO})(\mathrm{PPh})_{3}$ 与酒石酸衍生的手性双 膦配体 DIOP 形成的络合物应用于催化苯乙烯的氢甲酰 化反应中, 产物醛的异正比为 2.2 , 支链醛的 ee 值为 $23 \%$. 在此后的近二十年里，不对称氢甲酰化反应的研 究主要集中在 $\mathrm{Rh} /$ 膦和 $\mathrm{Pt} / \mathrm{Sn} /$ 膦两类催化体系的研究上, 但进展较为缓慢. 其中 $\mathrm{Pt} / \mathrm{Sn} /$ 膦催化体系在一些烯烃的 不对称氢甲酰化反应中虽能取得较高的对映选择性(最 高可达 $96 \%$ 的 $e e$ 值 $^{[8]}$ ), 但催化活性较低、支链醛选择 性差、且氢化副反应较严重等缺陷在一定程度上阻碍了 该类体系的进一步发展. 与 $\mathrm{Co}, \mathrm{Pt}$ 等催化剂相比, 近二 十年来发展的手性铑一膦催化剂在不对称氢甲酰化反应 中表现出活性较高、选择性好等优点，因此成为不对称 氢甲酰化研究的核心.在这类体系中，手性膦配体的种 类和立体电子特性对反应活性和选择性的控制起到了 非常重要的作用. 所以，在不对称氢甲酰化反应中，发 展新型的手性膦配体是提高催化效率和提升选择性控 制最主要的方法. 因此，本文将概述近年来几类重要的 手性膦配体在铑催化的烯烃不对称氢甲酰化反应中的 突破和进展

\section{1 手性双膦杂合配体}

不对称氢甲酰化的第一次突破，是 1993 年 Takaya 和 Nozaki 等 ${ }^{[9]}$ 采用铑-膦催化剂体系, 其中配体中是含 有两个手性联萗单元的膦-亚磷酸酯杂合配体 $(R, S)$ BINAPHOS，这类催化剂在苯乙烯衍生物、醋酸乙烯酯、 3-丁烯腈等多种单取代烯烃的不对称氢甲酰化中，能以 中等到良好的区域选择性优先获得支链醛，相应产物的 对映选择性良好到优秀，由于催化体系的高活性，反应 可以在较温和的反应条件进行且催化剂用量较低, 因此 成为该领域的一个里程碑式的工作(Eq. 1). 值得注意的 
是, BINAPHOS 中的两个手性联荎单元对此反应的手性 诱导都很重要, 且存在手性匹配的现象. 例如, 在苯乙 烯不对称氢甲酰化反应中, 将 $(R, S)$-BINAPHOS 用 $(R, R)$ BINAPHOS 替代, 导致反应活性明显降低, 对映选择性 也大幅下降.
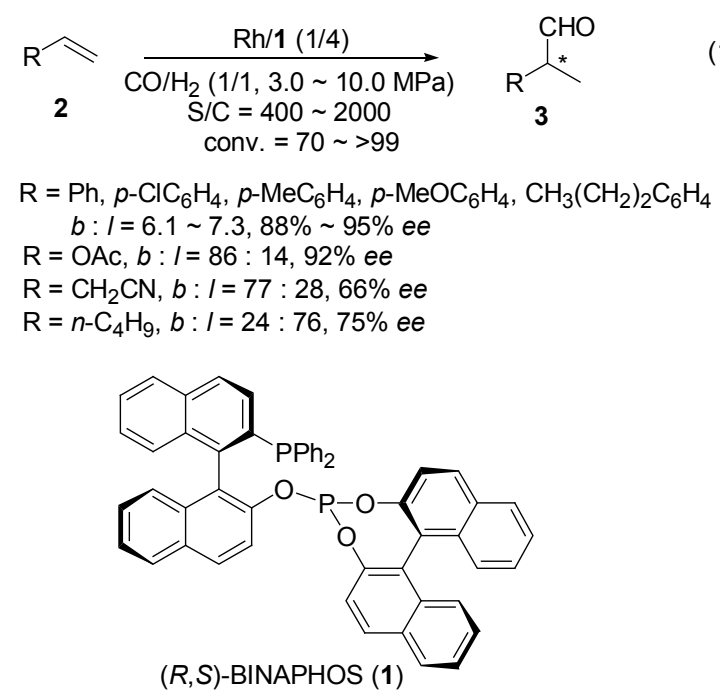

进一步研究表明, $(R, S)$-BINAPHOS 与铑形成的催 化剂在不对称氢甲酰化反应中表现出较为广泛的底物 适用性. 在 1,2-双取代的开链烯烃的不对称氢甲酰化中 (表 1) ${ }^{[10]}$, 对于 $\beta$-甲基苯乙烯 $(\mathbf{4 a} \sim \mathbf{4 b})$, 反式烯烃 $\mathbf{4 a}$ 氢甲 酰化获得优秀的支链醛区域选择性 $(b: l=98: 2)$ 和良 好的对映选择性(表 1, Entry 1, $80 \% e e$ ); 采用 $Z: E=1$ : 1 顺反烯烃混合物, 虽然区域选择性明显下降, 而对映 选择性则基本保持不变(表 1, Entry 2). 对于 1,2-二烷基 双取代的开链烯烃, 底物的构型差异对产物对映选择性 有明显的影响, 与反式烯烃 $4 d$ 相比, 顺式烯烃 $4 \mathrm{c}$ 的反 应所得到相应醛的 $e e$ 值更高(表 1, Entries 3 4).

表 $1 \mathrm{Rh} /(R, S)$-BINAPHOS 在一些 1,2-取代烯烃不对称氢甲酰 化发应中的应用 ${ }^{a}$

Table $1 \mathrm{Rh} /(R, S)$-BINAPHOS catalyzed asymmetric hydroformylation of some 1,2-disubstituted olefins

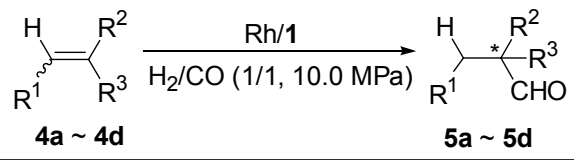

\begin{tabular}{|c|c|c|c|c|c|c|}
\hline Entry & Substrate & $\mathrm{R}^{1} \mathrm{R}^{2}$ & $\mathrm{R}^{3}$ & $T /{ }^{\circ} \mathrm{C}$ & $b: l$ & $e e / \%$ (conf.) \\
\hline 1 & $\mathbf{4 a}(E)$ & $\mathrm{Me} \mathrm{Ph}$ & $\mathrm{H}$ & 80 & $98: 2$ & $80(R)$ \\
\hline 2 & $\begin{array}{l}\mathbf{4 b} \\
(Z: E=1: 1)\end{array}$ & $\mathrm{Me} \mathrm{H}$ & $\mathrm{Ph}$ & 80 & $78: 22$ & $79(R)$ \\
\hline $3^{b}$ & $4 \mathrm{c}(Z)$ & $\mathrm{Me} \mathrm{H}$ & $\mathrm{Me}$ & 60 & - & $82(S)$ \\
\hline $4^{b}$ & $4 \mathbf{d}(E)$ & $\mathrm{Me} \mathrm{Me}$ & $\mathrm{H}$ & 60 & - & $48(S)$ \\
\hline
\end{tabular}

${ }^{a} \mathrm{~S} / \mathrm{C}=1000, \mathrm{Rh} / \mathbf{1}=1 / 4, \mathrm{CO} / \mathrm{H}_{2}=1 / 1(10.0 \mathrm{MPa}), 38 \sim 61 \mathrm{~h}$, benzene as solvent. ${ }^{b}$ Substrates were used in large excess.

Takaya 和 Nozaki 等 ${ }^{[10 a]}$ 还将 $(R, S)$-BINAPHOS/Rh(I)
体系成功应用于催化环内烯烃和杂环烯烃的不对称氢 甲酰化(Scheme 3). 对于环状烯烃䒢 6a 和 1,2-二氢荎 6b 的氢甲酰化, 其区域选择性与其母体苯乙烯相似，反应 优先形成醛基处于苯基 $\alpha$-位的碳原子的产物 $7 \mathbf{a}$ 和 $7 \mathbf{b}$, 且对映选择性达到良好至优秀(Scheme 4a). 通常情况 下，杂环烯烃的氢甲酰化选择性控制更为困难，原因是 杂原子的存在可能导致底物与铑-氢物种作用, 从而促 使烯烃发生异构化和环内双键迁移，造成区域选择性和 对映选择性下降 ${ }^{[3 b]}$. 例如在杂原子位于烯丙基的 2,5-二 氢呋喃(9a), Boc 或 $A c$ 保护 2,5-二氢吡咯 $9 b$ 和 $9 c$ 的不 对称氢甲酰化反应中, 可以良好至优秀的转化率得到 3位氢甲酰化产物 $10 \mathrm{a} \sim 10 \mathrm{c}$, 但对映选择性只有中等 (Scheme $4 \mathrm{~b}, 47 \% \sim 66 \% e e)^{[11]}$. 对于杂原子与 $\mathrm{C}=\mathrm{C}$ 双键 直接相连的 2,3-二氢呋喃和 2,3-二氢吡咯 $11 \mathbf{a} \sim 11 \mathbf{b}$, 氢 甲酰化反应的区域选择性(产物醛 12/13)较低, 相应产 物的 $e e$ 值可以达到中等至优秀 (Scheme $4 \mathrm{c})^{[11]}$. 将此催 化剂应用于七元杂环化合物 $\mathbf{1 4}$ 不对称氢甲酰化中, 则 以良好的对映选择性 $(68 \% \sim 73 \% e e)$ 得到了单一的手性 醛 15 (Scheme 4d) ${ }^{[11]}$.

Takaya 和 Nozaki 等 ${ }^{[10 b]}$ 对 $\mathrm{Rh}(\mathrm{I}) /(R, S)$-BINAPHOS 体系中与催化反应有关的羰基铑氢物种进行了详尽的 结构表征, 发现在氢甲酰化条件下,催化剂前体 $[\mathrm{Rh}(\mathrm{acac})(R, S)$-BINAPHOS $]$ 与 $\mathrm{CO}$ 和 $\mathrm{H}_{2}$ 反应得到中间体 物种 $\left[\mathrm{RhH}(\mathrm{CO})_{2}(R, S)\right.$-BINAPHOS $]$ (Eq. 2). 经过红外和 核磁光谱分析，发现该中间体结构近似为三角双锥构 型, 其中 BINAPHOS 配体与 $\mathrm{Rh}$ 之间采取单一的 eq-ax 配位模式, 即 BINAPHOS 配体中的 $\mathrm{PPh}_{2}$ 单元与两个 $\mathrm{CO}$ 分子处于铑的赤道位(equatorial, eq), 而 BINAPHOS 配 体中的亚磷酸酯单元和氢则处于三角双雉结构的轴向 位置(axial, ax). 这种单一的配位模式可以有效地减少竞 争过渡态的种类和数量, 他们认为这种结构特征对不对 称氢甲酰化反应中取得高的对映选择性十分重要, 并据 此提出了 $\mathrm{Rh}(\mathrm{I}) /(R, S)$-BINAPHOS 催化烯烃的不对称氢 甲酰化反应选择性控制模型.

$\mathrm{Rh}(\mathrm{I}) /(R, S)$-BINAPHOS 催化的烯烃不对称氢甲酰 化在某些药物的合成中取得了一些实际应用. 如七元杂 环化合物 14 通过 $\mathrm{Rh}(\mathrm{I}) /(R, S)$-BINAPHOS 催化氢甲酰化, 以中等的 $e e$ 值获得手性醛 15 , 后者经 4 步反应可得到 重要的手性构建单元 3-羟甲基-环丁酮内酯 (Scheme $4 \mathrm{a})^{[12]}$. Nozaki 等 ${ }^{[13]}$ 将 $\mathrm{Rh}(\mathrm{I}) /(R, S)$-BINAPHOS 催化体系 应用于 2-苯酰基-5-乙烯基噻吩的不对称氢甲酰化, 再 经氧化反应, 以 $84 \%$ 的 $e e$ 值得到非甾体类消炎药 $(S)$ Tiaprofenic acid (Scheme 4b). 此外, 在抗真菌试剂(+)ambruticin 的合成中, Liu 和 Jacobsen ${ }^{[14]}$ 将此催化剂成功 应用于其中一步关键的非对映选择性氢甲酰化反应中. 
(a)<smiles>c1ccc2[nH]ccc2c1</smiles>
$\operatorname{Rh}(\mathrm{acac})(\mathrm{CO})_{2} /(1 / 4)$-BINAPHOS

6a: $n=1$ 6b: $n=2$

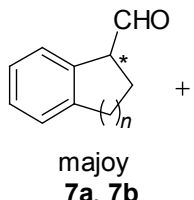

(b)

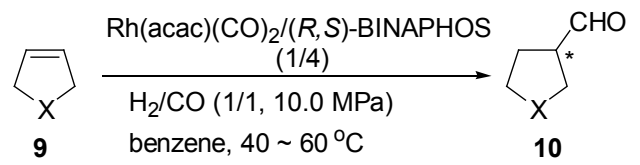

$\mathrm{S} / \mathrm{C}=400$

$$
\begin{aligned}
& \text { 10a: } X=0 \quad 75 \%, \quad 57 \% \\
& \text { 10b: } X=\text { NBoc } \quad 98 \%, \quad 47 \% \\
& \text { 10c: } X=N A c \quad 92 \%, \quad 66 \%
\end{aligned}
$$

(c)

$$
\begin{aligned}
& \mathrm{Rh}(\mathrm{acac})(\mathrm{CO})_{2} /(R, S) \text {-BINAPHOS } \\
& \begin{array}{cc} 
& \\
& \mathrm{H}_{2} / \mathrm{CO}(1 / 1,10.0 \mathrm{MPa}) \\
11 & \text { benzene, } 60^{\circ} \mathrm{C} \\
& \mathrm{S} / \mathrm{C}=200 \sim 400
\end{array}
\end{aligned}
$$

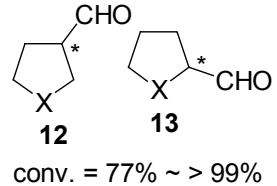

a: $\mathrm{X}=\mathrm{O},\left[(R, S)-3,3^{\prime}-\mathrm{Me}_{2}-\mathrm{BINAPHOS}\right], 12 / 13=1 / 1,12$ (38\% ee) b: $X=$ NBoc, $12 / 13=33 / 67,12(71 \%$ ee $), 12(97 \%$ ee $)$

(d)

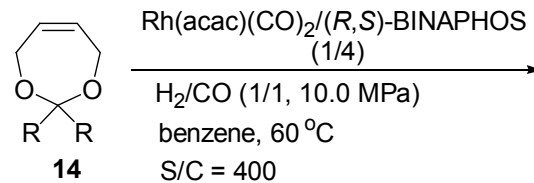

a: $\mathrm{R}=\mathrm{H}$

b: $\mathrm{R}=\mathrm{CH}_{3}$

scheme 3

由此可见, $\mathrm{Rh} /(R, S)-\mathrm{BINAPHOS}$ 催化剂在多种类型 烯烃的不对称氢甲酰化反应中表现出了良好的底物适 用性, 其中一些产物的 $e e$ 值超过 $90 \%$. 当然像所有的优 秀催化剂一样, $\mathrm{Rh} /(R, S)$-BINAPHOS 催化体系也存在一 定的局限性, 除反应压力较高外, 氢甲酰化反应的区域 选择性和对映选择性随底物类型不同而有较大变化, 如 前面 Eq. 1 中当烯烃的取代基团为非官能团化的供电子 的烷基时, 产物以直链醛为主, 同时支链醛的 $e e$ 值也所 降低. 尽管如此，这是烯烃的不对称氢甲酰化反应中第 一例有较广泛底物适用范围和高对映选择性的铑催化 体系, 加之其良好的催化活性, 因此至今仍被认为是不 对称氢甲酰化反应中最优秀的催化体系之一, 并引发了 人们对铑催化不对称氢甲酰化反应中新配体的进一步 (a)

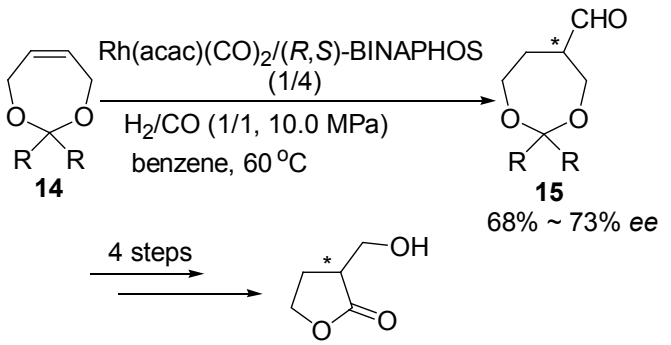

(1) [Rh- $(R, S)-\mathrm{MeO}-\mathrm{BINAPHOS}]$

(b)<smiles>C=Cc1ccc(C(=O)c2ccccc2)s1</smiles>

(2) $\mathrm{NaClO}_{2}, 2$-methyl-2-butene $\mathrm{NaH}_{2} \mathrm{PO}_{4}$ (aq.)

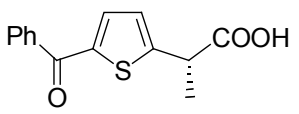

(S)-Tiaprofenic acid $84 \%$ ee

\section{Scheme 4}
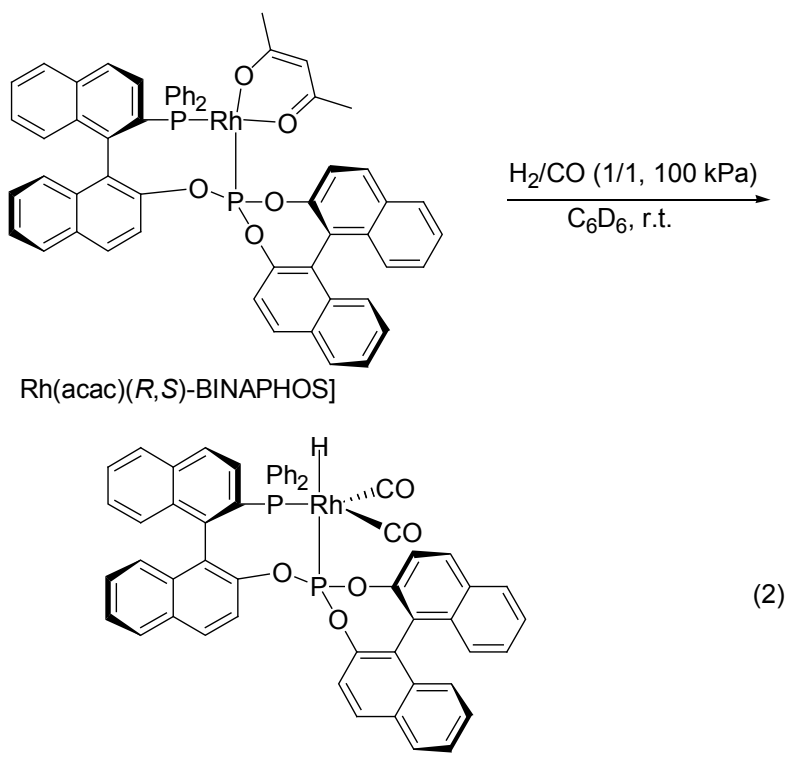

$\left[\mathrm{RhH}(\mathrm{CO})_{2}(R, S)-\mathrm{BINAPHOS}\right]$

探索.

2006 年, 张绪穆等 ${ }^{[15]}$ 发展了一类新的手性双齿膦亚膦酰胺杂合配体 $(R, S)$-NEt-Yanphos．该配体骨架与 $(R, S)$-BINAPHOS 结构相似，也含有两个手性联萘和一 个 $\mathrm{PPh}_{2}$ 配位单元, 但与荟骨架相连的氧原子改为 $\mathrm{NEt}$, 从而改变了配体的电子性质. 通过 MM2 分子力学模拟, 发现与 $(R, S)$-BINAPHOS 相比，该配体与 $\mathrm{Rh}$ 形成的中间 体 $\left\{\mathrm{Rh}[(R, S)-\mathbf{1 6}] \mathrm{H}(\mathrm{CO})_{2}\right\}$ 结构中 P-Rh-P 活性位点附近的 手性空间更加紧密，从而可以提供一个更深、位阻更大 的反应空间. 该配体应用于铑催化的苯乙烯衍生物和醋 酸乙烯酯的不对称氢甲酰化反应中，表现出了优秀的对 映选择性(Scheme $5 \mathrm{a})$, 反应在较低的压力 $(2.0 \mathrm{MPa})$ 下 
进行, 即可获得优秀或定量的底物转化, 且手性醛的区 域选择性与 $(R, S)$-BINAPHOS/Rh 体系相当, 而对映选择 性则明显高于 $(R, S)$-BINAPHOS/Rh 体系. 同时, $\mathrm{Rh}(\mathrm{I}) /$ $(R, S)$-NEt-Yanphos 在多种烯丙基酰胺不对称氢甲酰化 反应中也表现出较高的反应活性、中等的支链醛选择性 和优秀的对映选择性, 其中 N-Boc 保护的丙烯胺经不对 称氢甲酰化得到的手性醛在药物合成中有重要应用前 景, 经氧化或者氢化得到的 $\beta$-氨基酸和 1,3-胺基醇都是 重要的合成片段, 另外其氢甲酰化产物也可用于白细胞 粘附抑制剂 Cyclamenol A 的合成(Scheme 5b) ${ }^{[16]}$.

(a)

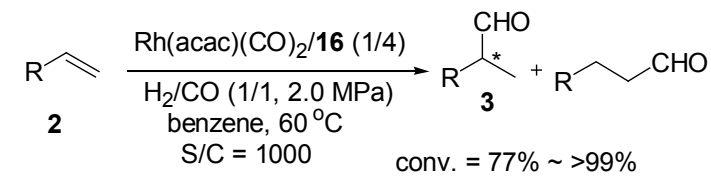

$\mathrm{R}=\mathrm{Ph}, p-\mathrm{ClC}_{6} \mathrm{H}_{4}, p-\mathrm{CH}_{3} \mathrm{C}_{6} \mathrm{H}_{4}, p-\mathrm{CH}_{3} \mathrm{OC}_{6} \mathrm{H}_{4}, p-\mathrm{FC}_{6} \mathrm{H}_{4}$, $o-\mathrm{FC}_{6} \mathrm{H}_{4}, p-t-\mathrm{BuC}_{6} \mathrm{H}_{4}, b: I=6.1 \sim 10.1,88 \% \sim 95 \%$ ee $\mathrm{R}=\mathrm{OAc}, b: I=93: 7,96 \%$ ee
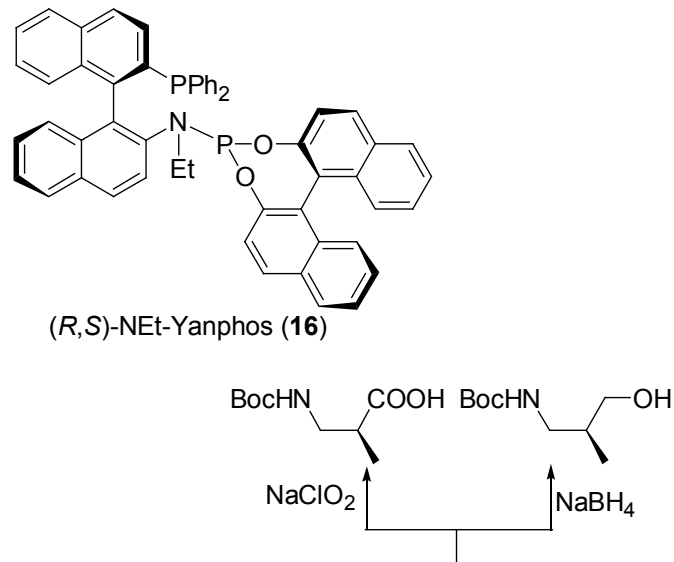

(b) $\mathrm{BocHN} \curvearrowright \frac{\mathrm{Rh}(\mathrm{acac})(\mathrm{CO})_{2} / 16(1 / 4)}{\mathrm{CO} / \mathrm{H}_{2}(1 / 1.1 .0 \mathrm{MPa}),} \mathrm{BocHN}$ toluene, $40^{\circ} \mathrm{C}, 20 \mathrm{~h} \quad b: I=66: 34$ $\mathrm{S} / \mathrm{C}=1000$ $94 \%$ ee conv. $=61 \%$

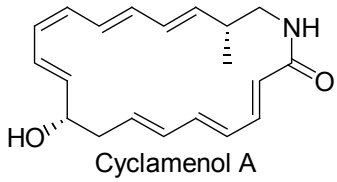

\section{Scheme 5}

前面提到, 五元杂环烯烃的不对称氢甲酰化由于烯 烃异构化等竞争反应, 导致选择性控制困难. 最近, Reek 等 ${ }^{[17]}$ 报道了一类新型手性双齿膦-亚磷酸二酯杂合 配体 17 (Eq. 3), 该配体中含有刚性的 9,9-二甲基氧杂葱 骨架，与金属 $\mathrm{Rh}$ 配位时 P-Rh-P 夹角(bite angle)较大, 所 形成的中间体 $\left\{\mathrm{Rh}[(\mathrm{S})-17] \mathrm{H}(\mathrm{CO})_{2}\right\}$ 采取 ee-配位的三角双 雉结构, 在 2,5-二氢呋喃(9a)的不对称氢甲酰化反应中, 得到了单一的产物 12a, 反应 $40 \mathrm{~h}$ 底物的转化率可达
$90 \%$, 产物 12a 的 $e e$ 值为 $91 \%$. 但对于 2,3-二氢呋喃和 五元含氮杂环烯烃的不对称氢甲酰化, 则仍然存在转化 率不高或对映选择性较低等问题.

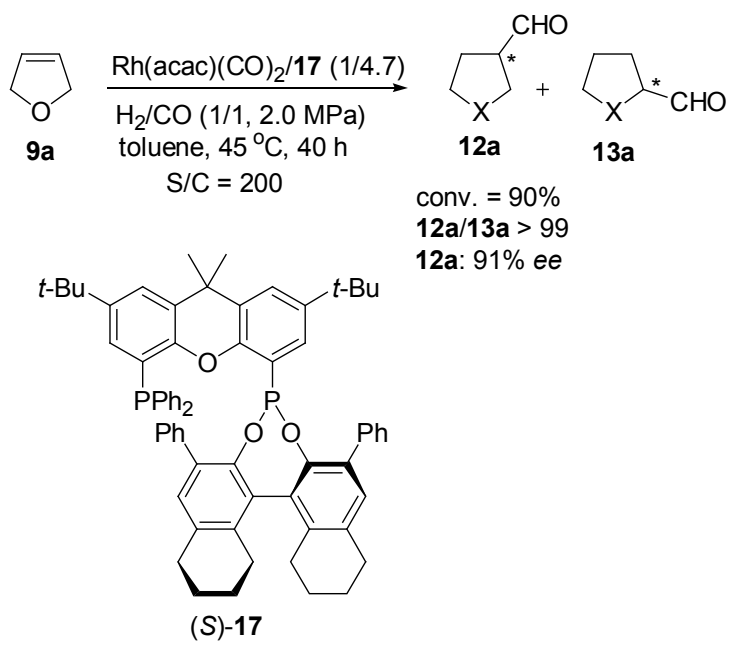

对于非官能团化的烷基取代的烯烃不对称氢甲酰 化反应，其产物通常以直链醛为主，因此烷基单取代的 烯烃是不对称氢甲酰化反应的一类有较大挑战性的底 物, 相关研究工作报道较少. 2012 年, Cobley 和 Clarke 等 ${ }^{[18]}$ 以手性联苯为骨架发展了一类手性膦-亚膦酸酯杂 合配体 $\left(S_{\mathrm{ax}}, S, S\right)$-bobphos (20), 并将其应用于 $\mathrm{Rh}(\mathrm{I})$ 催化 的烷基单取代烯烃的不对称氢甲酰化反应(Eq. 4), 发现 在较温和反应条件下 $\left(16 \sim 60{ }^{\circ} \mathrm{C}, 500 \mathrm{kPa}\right)$, 烯丙位芳 基、烷基、氧基或酰胺基取代的烯烃底物 18 均可以顺 利发生反应，以良好到定量的收率、较高的区域选择性 和良好至优秀的对映选择性获得支链醛，光学活性醛的 $e e$ 最高可达 $92 \%$, 反应的异正比最高达到 $10 ： 1$.
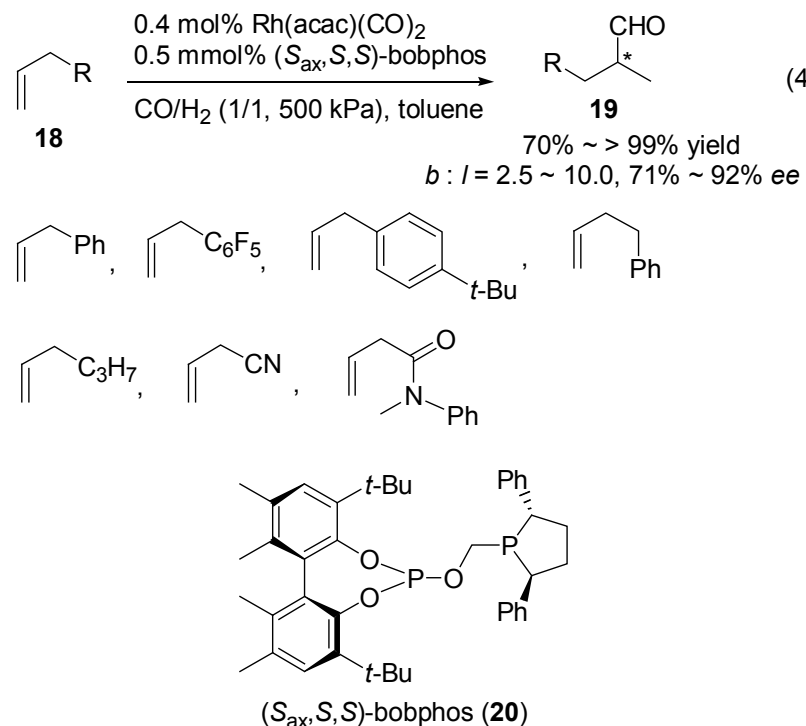

从上面的讨论可以看出, 迄今为止所发展的手性 膦-磷杂合双齿配体与铑组成的催化体系在一些烯烃, 
其中主要是在单取代烯烃的不对称氢甲酰化反应表现 出较好的支链醛区域选择性和对映选择性. 像类似于 $(R, S)$-BINAPHOS/Rh 催化剂广泛底物适用性的杂合双 齿配体仍然较少, 除 $(R, S)$-NEt-Yanphos 之外, 配体 17 和 $\left(S_{\mathrm{ax}}, S, S\right)$-bobphos (20)对于较困难的特定烯烃底物, 如一 些五元杂环烯烃和烷基取代的烯烃能够表现出优良的 催化效能. 因此, 在烯烃的不对称氢甲酰化反应中, 继 续发展具有广泛底物适用性的新型手性杂合配体, 仍是 一个有潜力的研究方向.

\section{2 手性双齿亚磷(膦)酸酯配体}

1993 年, 美国联碳公司(UCC)在专利中报道了一类 以手性 2,4-戊二醇衍生的双齿亚磷酸酯配体 21 (Eq. 5), 在铑催化苯乙烯的不对称氢甲酰化反应取得了很好的 区域选择性 $(b: l=96: 4)$ 和优秀的对映选择性 $(90 \%$ $e e)^{[19]} .2005$ 年, Klosin 等 ${ }^{[20]}$ 又将此配体分别应用于醋酸 乙烯酯和 3-丁烯腈的不对称甲酰化反应中, 相应支链醛 的区域选择性达到良好到优秀, 但产物的 ee 值均不理 想 $(50 \%$ 和 $13 \% e e$ ) (Eq. 5). UCC 的专利中还提到采用 Chiraphite (21) 为配体, 通过芳基乙烯的不对称氢甲酰 化一氧化方法, 以良好的对映选择性方便地合成非甾体 类镇痛消炎药䒬普生 $[(S)$-Naproxen] $(85 \% e e)$ 和布洛芬 [(S)-Ibuprofen] $(82 \% e e)^{[19 a]}$.

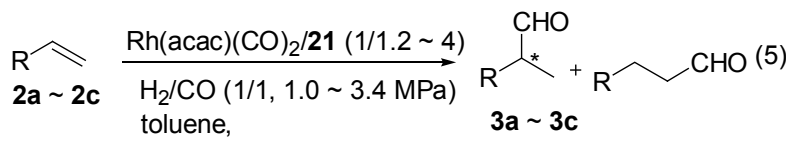

$$
\begin{aligned}
& \mathrm{S} / \mathrm{C}=4000 \sim 5000 \quad \text { conv. }=38 \% \sim 100 \%
\end{aligned}
$$

3a: $\mathrm{R}=\mathrm{Ph}, b: I=96: 4,90 \%$ ee

3b: $\mathrm{R}=\mathrm{OAc}, b: I=190: 1,50 \%$ ee

3c: $\mathrm{R}=\mathrm{CH}_{2} \mathrm{CN}, b: I=5.5: 1,13 \%$ ee

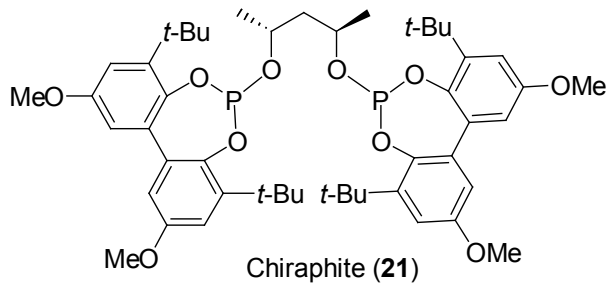

2001 年, Diéguez 和 Claver 等 ${ }^{[21]}$ 以 $D-(+)$-葡萄糖为 骨架发展了一类手性双齿亚磷酸酯配体 22 (Scheme 6). 该配体与铑形成的催化体系在几种苯乙烯衍生物的不 对称氢甲酰化中, 取得了优秀的区域选择性和对映选择 性, 光谱分析表明催化物种 $\left[\mathrm{HRh}(\mathbf{2 2})(\mathrm{CO})_{2}\right]$ 的手性诱导 能力与其很强的双赤道位配位趋向有明显关联. 在此基 础上, Diéguez 和 Claver 等 ${ }^{[22]}$ 进一步对铑催化的醋酸乙 烯酯、2,3-二氢呋喃和 2,5-二氢呋喃的氢甲酰化反应进 行了考察, 结果表明, 在醋酸乙烯酯的不对称氢甲酰化 反应中, 可以取得优秀的区域选择性和中等的对映选择
性效果(Scheme 6a), 在五元杂环烯烃如 2,3-二氢呋喃 (11a)和 2,5-二氢呋喃(9a)的不对称氢甲酰化反应中，以 中等至优秀的区域选择性以及中等的对映选择性得到 光学活性手性醛 10a (74\% 75\% ee, Schemes 6b, 6c).

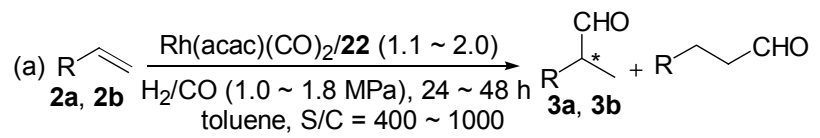

3a: (22a), $\mathrm{R}=\mathrm{Ph}, p-\mathrm{MeOC}_{6} \mathrm{H}_{4}, p-\mathrm{FC}_{6} \mathrm{H}_{4}$

conv. $=80 \% \sim 83 \%, b: l=70.4 \sim 82.3,89 \% \sim 91 \%$ ee

3b: (22b), $\mathrm{R}=\mathrm{OAc}$, conv. $=43 \%, b: l=99: 1,73 \%$ ee (b)

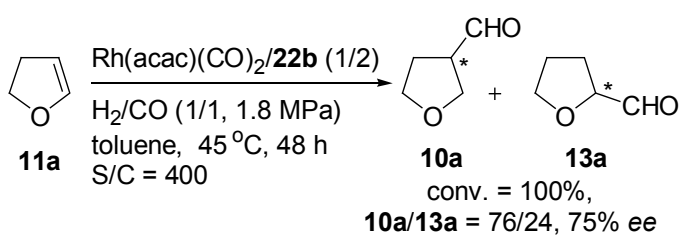

(c)

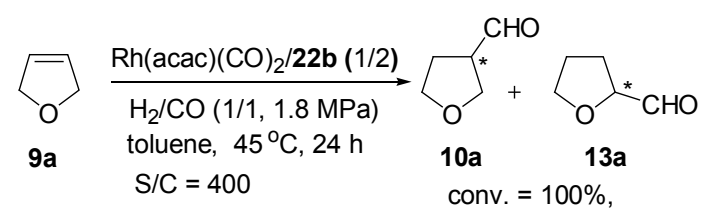

$\mathrm{R}$

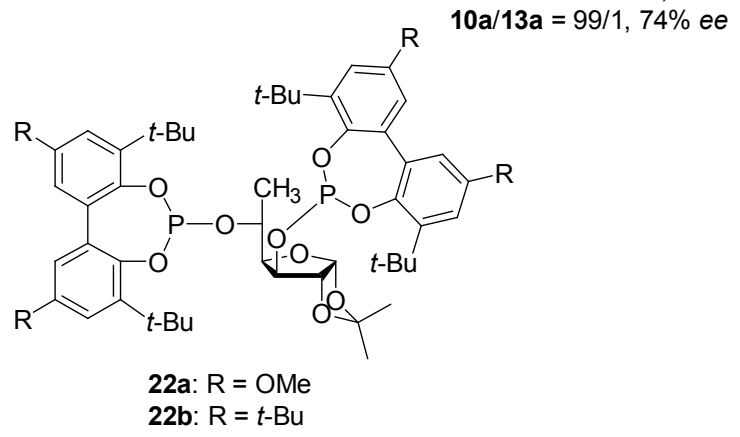

\section{Scheme 6}

2004 年, Cobley, Klosin 和 Whiteker 等 ${ }^{[23]}$ 报道了一类 联苯骨架的手性双齿亚磷酸酯配体 Kelliphite (23)在 Rh 催化的 3-丁烯腈不对称氢甲酰化反应中的应用(Eq. 6). 与前面的手性双齿亚磷酸酯配体不同，此配体以非手性 的联苯为骨架. 在 3-丁烯腈的氢甲酰化反应中, $\mathrm{Rh} / \mathbf{2 3}$ 催 化剂表现出优秀的支链醛选择性 $(b: l=20)$ 和良好的对 映选择性 $(80 \% e e)$, 催化活性也比较高 $\left(\mathrm{TOF}=625 \mathrm{~h}^{-1}\right)$. 进一步研究表明, 该配体与 $\mathrm{Rh}(\mathrm{acac})(\mathrm{CO})_{2}$ 形成的催化 剂在苯乙烯和醋酸乙烯酯的不对称氢甲酰化反应均表 现出优秀的区域选择性, 但对映选择性则有很大差异 $(16 \% \mathrm{vs} 88 \%$ ee $)$. 从手性双亚磷酸酯配体 21,22 和 23 在 几种典型单取代烯烃底物的不对称氢甲酰化反应结果 来看，特定的底物类型对于不同配体结构的催化剂选择 性有着显著的影响，进一步体现出配体骨架设计在不对 称氢甲酰化反应中的重要意义.

2008 年, 丁奎岭和夏春谷等 ${ }^{[24]}$ 以刚性较强的苯环 


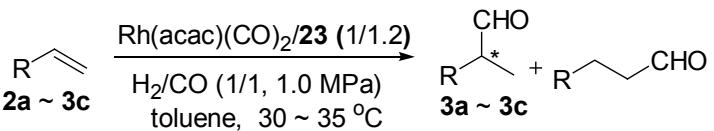

$$
\begin{aligned}
& \mathrm{S} / \mathrm{C}=300 \sim 1500 \quad \text { conv. }=19.4 \% \sim 100 \%
\end{aligned}
$$

3a: $\mathrm{R}=\mathrm{Ph}, b: I=98: 2,16 \%$ ee

3b: $\mathrm{R}=$ OAc, $b: I=99: 1,88 \%$ ee

3c: $\mathrm{R}=\mathrm{CH}_{2} \mathrm{CN}, b: I=20: 1,80 \%$ ee

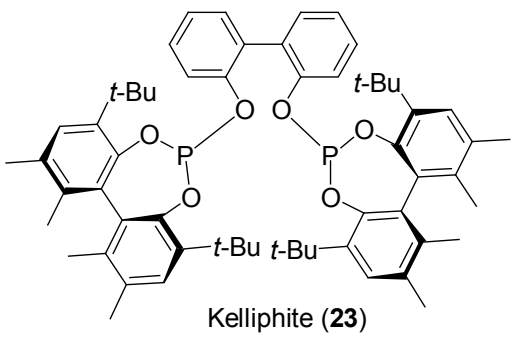

作为骨架发展了一类手性双齿亚膦酸二酯配体 24 (Eq. 7). 与磷相连的两个酚氧环具有较大的位阻, 可以在 $\mathrm{Rh}$ 催化中心周围提供一个有较大位阻差异的反应空间, 从 而有利于反应的区域选择性和对映选择性控制. 这类催 化剂在苯乙烯、醋酸乙烯酯和 3-丁烯腈的氢甲酰化反应 中, 表现出较高的催化活性、良好的区域选择性 $(b: l=$ $3.2 \sim 40.7)$ 和良好到优秀的对映选择性(70\% 91\% ee), 尤其在醋酸乙烯酯不对称氢甲酰化的反应中, 可以得到 $91 \%$ ee 值的手性醛. 丁奎岭和夏春谷等 ${ }^{[25]}$ 还进一步报 道了一类以构象较灵活的二茂铁为骨架的手性双齿亚 膦酸酯配体 25 (Eq. 8), 此类配体在 Rh 催化的苯乙烯和 醋酸乙烯酯的不对称氢甲酰化反应中, 表现出很好的区 域选择性, 但仅在醋酸乙烯酯的反应中表现出较好的对 映选择性.

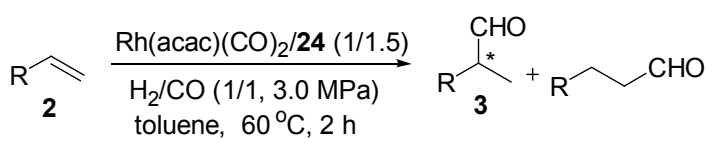

$$
\begin{aligned}
& \mathrm{S} / \mathrm{C}=500 \quad \text { conv. }=87 \% \sim 99 \%
\end{aligned}
$$

$\mathrm{R}=\mathrm{CH}_{2} \mathrm{CN}, b: I=3.2,77 \%$ ee

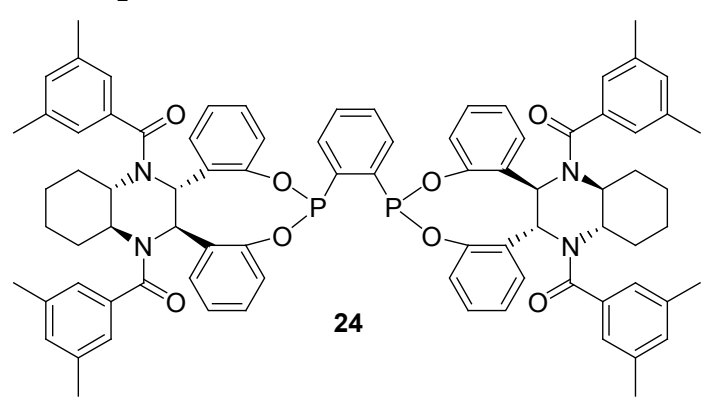

在铑催化的不对称氢甲酰化反应中，与亚膦酸酯相 比，手性双齿膦氮杂环配体的报道则较少. 早在 2000 年, Wills 等 ${ }^{[26]}$ 报道了以苯环为骨架的手性双齿膦氮杂

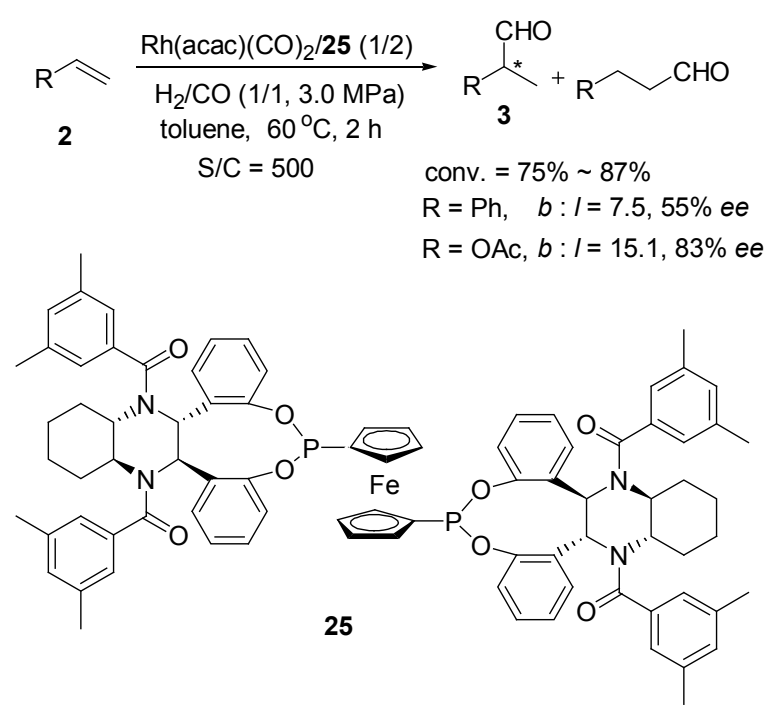

环(diazaphospholidine)配体 ESPHOS (26)在 Rh 催化的醋 酸乙烯酯和苯乙烯不对称氢甲酰化反应中的应用(Eq. $9)$, 该类催化剂虽然在醋酸乙烯酯的反应中, 获得了异 正比为 93.5/6.5、支链醛 $e e$ 值为 $90 \%$ 产物, 但在苯乙烯 的不对称氢甲酰化反应，产物则是消旋的。

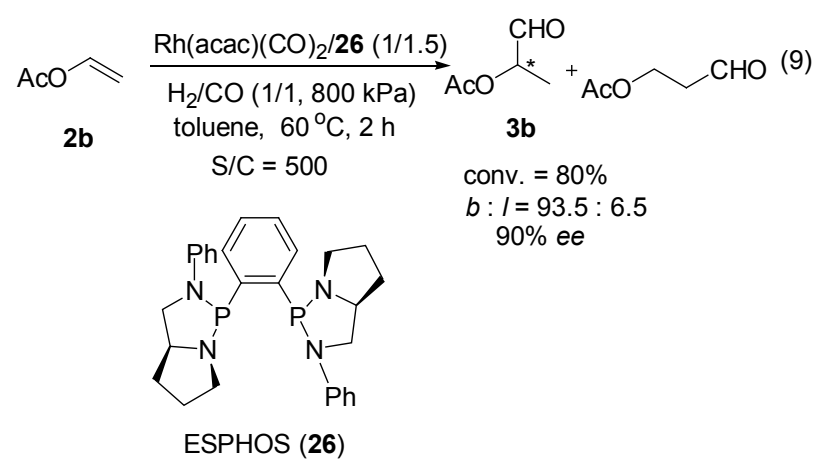

由上可见，双齿亚膦酸酯配体已经在一些烯烃底物 的不对称氢甲酰化反应中表现出优良的区域选择性和 对映选择性，是一类重要的手性配体 ${ }^{[27]}$. 但另一方面, 目前所发展的手性双齿亚膦酸酯配体还存在底物适用 范围较窄等问题. 另外, 在其它类型的烯烃不对称氢甲 酰化反应的研究也有待拓展.

\section{3 手性双齿膦配体}

2005 年, Klosin 和 Landis 等 ${ }^{[20]}$ 发展了一类手性双3,4-二氮磷杂环戊烷配体 $(S, S, S)$-Bisdiazaphos (27) (Scheme 7). 该配体以 1,2-苯基连接的两个 3,4-二氮磷杂 环戊烷单元为核心骨架，具有多个手性中心. 此类配体 在 Rh(I)催化苯乙烯、醋酸乙烯酯、3-丁烯腈的不对称氢 甲酰化中, 在 $1: 5000$ 的催化剂用量、 $80{ }^{\circ} \mathrm{C}$ 和 $1.0 \mathrm{MPa}$ $\mathrm{H}_{2} / \mathrm{CO}(1 / 1)$ 条件下反应 $3 \mathrm{~h}$, 三种底物都可以实现定量 的转化, 并以较高的区域选择性 $(b: l=4.1 \sim 37 / 1)$ 和良 
好到优秀的对映选择性获得支链醛 $(82 \% \sim 96 \%$ ee $)$ (Scheme 7a). 其中, $\mathrm{Rh}(\mathrm{I}) /(S, S, S)$-Bisdiazaphos 催化的醋 酸乙烯酯的不对称氢甲酰化可以成功放大到 $135 \mathrm{~g}$ 底物, 在十万分之一的催化剂用量下, $80{ }^{\circ} \mathrm{C}$ 下反应 $5 \mathrm{~h}$ 达到 $97 \%$ 的转化(95\%ee, $b: l=28.7)$, TOF 高达 $19400 \mathrm{~h}^{-1[28]}$. 2010 年, Stahl 和 Landis 等 ${ }^{[29]}$ 又将此配体成功应用于铑 催化的乙烯基酰胺类底物和烯丙基类化合物的不对称 氢甲酰化反应，对于烯基酰胺类底物的氢甲酰化反应， 底物可以定量转化, 产物的区域选择性和对映选择性最 高均可达优秀(Scheme 7b); 对于烯丙醇、烯丙醚和烯丙 基酰胺的不对称氢甲酰化反应, 支链醛的区域选择性 ( $b: l=0.3 \sim 2.6$ ) 中等，但对映选择性达到 $95 \% \sim 97 \%$ (Scheme 7b). Landis 等 ${ }^{[30]}$ 还将此配体应用于铑催化的 1,2-取代芳基烯烃的不对称氢甲酰化反应(Scheme 7c), 对于顺式 $\beta$-甲基苯乙烯氢甲酰化, 可以获得良好的支链 醛区域选择性 $(b: l=11)$ 和优秀的对映选择性 $(92 \% e e)$, 而对于反式 $\beta$-甲基苯乙烯的氢甲酰化, 虽然区域选择性
有所增加 $(b: l=20)$, 但对映选择性较差 $(18 \% e e)$. 同 样，在顺式二苯乙烯的不对称氢甲酰化反应中，也可以 取得优秀的对映选择性 $(93 \% e e)$; 对于环状烯烃狮的氢 甲酰化反应，以优秀的区域选择性优先形成醛基处于苯 基 $\alpha$-位碳原子上的产物，其对映选择性良好( $83 \% e e$ ) (Scheme 7c). Stahl 和 Landis 等 ${ }^{[29]}$ 的研究工作还表明, $\mathrm{Rh}(\mathrm{I}) /(S, S, S)$-Bisdiazaphos 催化体系同样适用于五元含 氮杂环烯烃的不对称氢甲酰化反应. 在 $N$-Boc 保护的 2,3-二氢吡咯的反应中，底物基本可以完全转化，醛基 主要位于 2 位碳原子上, 其反应的区域选择和对映选择 性均可达到优秀(Scheme 7d). 同样, 对于 $N$-Boc 保护的 2,5-二氢吡咯, 醛基位于 3 位碳原子上, 产物 $\mathbf{1 3 b}$ 区域选 择性可达 15：1, 且 $e e$ 值为 91\% (Scheme 7e).

$\mathrm{Rh}(\mathrm{I}) /(S, S, S)$-Bisdiazaphos 催化的烯烃不对称氢甲 酰化在一些药物的合成中获得了实际应用. 2010 年, Landis 和 Stahl 等 ${ }^{[29]}$ 将 $\mathrm{Rh}(\mathrm{I}) /(S, S, S)$-Bisdiazaphos 体系应 用于 1,1-双取代烯烃 30 的不对称氢甲酰化反应，以高的 (a)

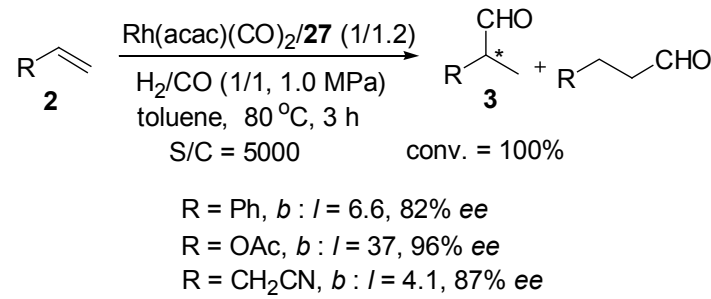

(b)

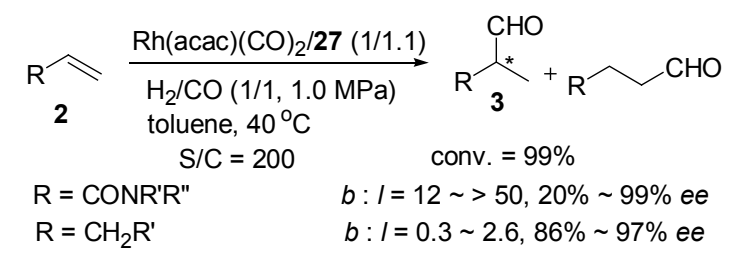

(c)

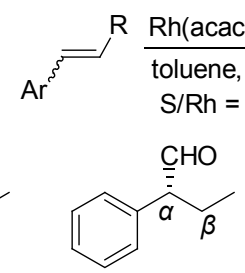

原料: 顺式烯烃

$\alpha / \beta=11 / 1$ $\alpha: 92 \%$ ee

原料: 反式烯烃 $\alpha l \beta=20 / 1$ $\alpha: 18 \%$ ee<smiles>OC[C@@H](Cc1ccccc1)c1ccccc1</smiles>

原料: 顺式烯烃 $93 \%$ ee (d)

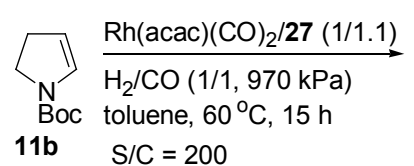

(e)

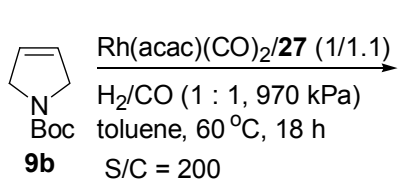<smiles>[O+]=C[C@@H]1CCCN1[18OH]</smiles>

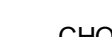<smiles>O=C[C]1CCN(C(=O)OCc2ccccc2)C1</smiles>
13b

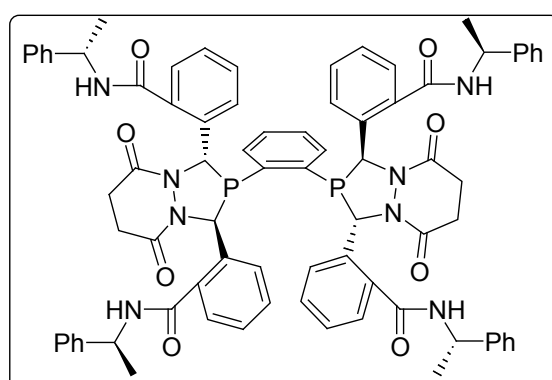

$(S, S, S)$-Bisdiazaphos (27)<smiles>O=C[C@H]1CCc2ccccc21</smiles>

$\alpha / \beta=20 / 1$

$\alpha: 83 \%$ ee
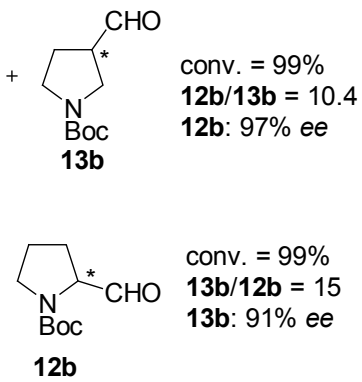

Scheme 7 
区域选择性优先形成直链醛 31, 且对映选择性良好 (74\% ee) (Scheme 8a), 手性醛 31 可进一步转化为 $\alpha$ 或 $\beta$ 氨基酸. 2012 年, Burke 等 ${ }^{[31]}$ 将 $\mathrm{Rh}(\mathrm{I}) /(S, S, S)$-Bisdiazaphos 用于 $N, O$-杂环戊烯 28 的不对称氢甲酰化, 合成了一类 重要手性中间体 29 (Garner 醛). 在此反应中, 醛基主要 位于与 N-Boc 相连碳的位置, 以优秀的区域选择性 $(b / l=20)$ 和对映选择性 $(97 \% e e)$ 得到目标产物(Scheme $8 b)$. 同年, Burke 和 Risi ${ }^{[32]}$ 将此体系应用于抗菌药 $(+)-$ Patulodide $\mathrm{C}$ 的合成, 顺式烯烃底物 33 经不对称氢甲酰 化反应后, 不需要分离直接应用于进一步的转化, 最终 以 96.6:3.4 的 $d r$ 值得到(+)-Patulodide C (Scheme $8 \mathrm{c})$.

(a)

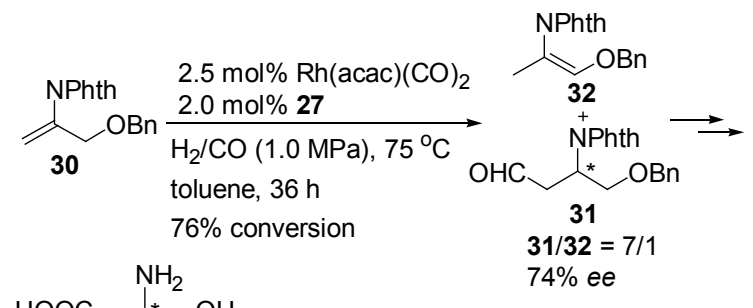

(b)

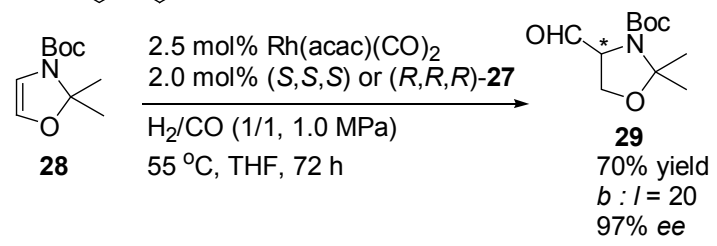

(c)
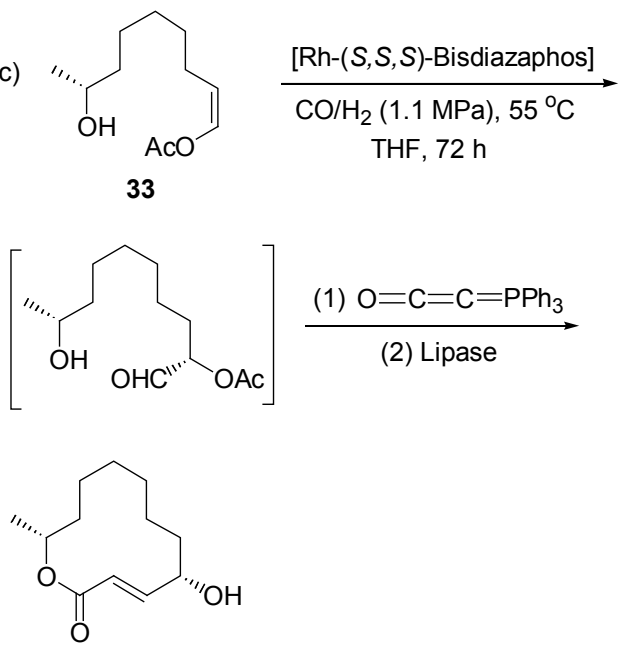

(+)-Patulodide C $d r=96.6 / 3.4$

\section{Scheme 8}

由此可见, $(S, S, S)$-Bisdiazaphos (27)可以应用于铑催 化的多种类型烯烃的不对称氢甲酰化反应, 并能以高催 化活性、良好到优秀的区域选择性和对映选择性得到相 应的光学活性醛类产物. 与 $(R, S)$-BINAPHOS 相比, 配 体 $(S, S, S)$-Bisdiazaphos 有着更好的底物适用性. 因此, 配体 $(S, S, S)$-Bisdiazaphos 是继 $(R, S)$-BINAPHOS 之后, 在 不对称氢甲酰化研究领域中的又一个突破.
Klosin 等 ${ }^{[33]}$ 进一步研究了手性双磷杂环戊烷配体 Ph-bpe (34)在铑催化的烯烃不对称氢甲酰化中的应用 (Eq. 10). 该配体中的两个五元磷杂环以较柔性的 $\left(\mathrm{CH}_{2}\right)_{2}$ 单元连接, 磷杂五元环上的苯基可在催化剂活性位点附 近形成较大的空间位阻. 此类催化剂在苯乙烯、醋酸乙 烯酯和 3-丁烯腈等单取代烯烃的的氢甲酰化反应中，表 现出较高的反应活性，良好到优秀的区域选择性和对映 选择性 $(82 \% \sim 94 \%$ ee $)$, 例如在五千分之一的催化剂的 用量下, 苯乙烯和醋酸乙烯酯不对称氢甲酰化的异正比 分别高达 $145: 1$ 和 $340: 1$.

$$
\begin{aligned}
& 2 \underset{\begin{array}{l}
\mathrm{H}_{2} / \mathrm{CO}(1 / 1,1.0 \mathrm{MPa}) \\
\text { toluene }, 80^{\circ} \mathrm{C}, 3 \mathrm{~h} \\
\mathrm{~S} / \mathrm{C}=5000 \quad \text { conv. }=52 \% \sim 96 \%
\end{array}}{\mathbf{R}=\mathrm{CHO}} \\
& \mathrm{R}=\mathrm{Ph}, b: I=145: 1,94 \% \text { ee } \\
& \mathrm{R}=\mathrm{OAc}, b: I=340: 1,82 \% \text { ee } \\
& \mathrm{R}=\mathrm{CH}_{2} \mathrm{CN}, b: I=7.1: 1,90 \% \text { ee }
\end{aligned}
$$

双膦配体 Tunephos 最早是由张绪穆等 ${ }^{[34]}$ 发展, 并 应用于钉催化的不对称氢化反应. 2008 年, Rubin 和 Sherrill ${ }^{[35]}$ 将手性双膦配体 $(R)$-C3-Tunephos 应用于铑催 化的 3,3-双取代环丙烯的不对称氢甲酰化反应，以高的 非对映选择性 $(d r=5 \sim 25: 1)$ 、良好的收率 $(54 \% \sim 86 \%$ yield)及对映选择性 $(57 \% \sim 83 \% e e)$ 得到含有两个手性中 心的醛类产物(Eq. 11).

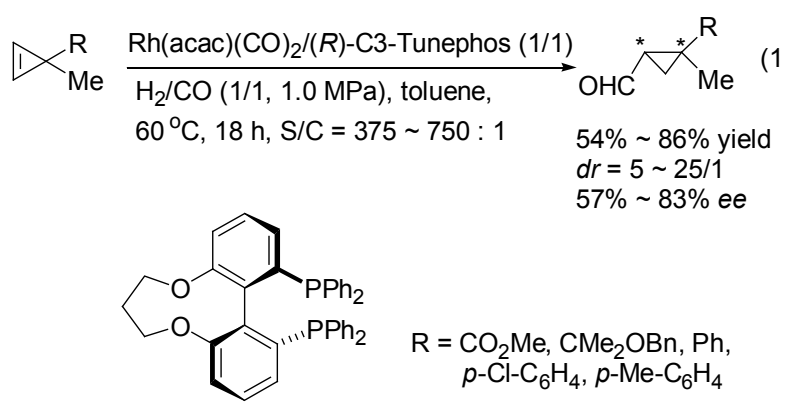

(R)-C3-Tunephos

配体 $(R, R)-\operatorname{Benz} \mathrm{P}^{*}(\mathbf{3 5})$ 是一类具有较大空间位阻的 手性双膦配体，最早由 Imamoto 等 ${ }^{[36]}$ 设计合成. 该配体 以苯环为骨架，手性中心位于两个磷原子上，在空气中 具有一定的稳定性. 2012 年, Buchwald 等 ${ }^{[37]}$ 将此配体应 用于铑催化的 $\alpha$-烷基丙烯酸酯 36 的不对称氢甲酰化反 应中, 以较高的产率和良好到优秀的对映选择性获得直 链醛产物 37 (Eq. 12). 对于 1,1-双取代的烯烃底物的氢 
甲酰化反应，由于立体位阻的影响，一般以较高的区域 选择性优先形成直链醛产物 ${ }^{[38]}$. 烯烃底物 36 的 $\alpha$-位为 含氢原子的烷基取代基, 在氢甲酰化反应条件下容易发 生烯烃的异构化, 从而影响化学选择性和产物收率. 因 此，当底物的 $\alpha$ 位为甲基或亚甲基时，产物的收率中等. 当底物的 $\alpha$ 位为三级碳时, 如异丙基、环戊基和环已基, 醛的产率和 $e e$ 随着底物位阻的增加而提高.

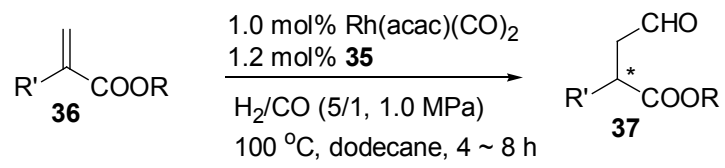

$\mathrm{R}=\mathrm{Me}, \mathrm{Et}$

$\mathrm{R}^{\prime}=\mathrm{Me}, \mathrm{Et}, \mathrm{Bn}, \mathrm{TBSO}\left(\mathrm{CH}_{2}\right)_{3}$, yield: $54 \% \sim 68 \%, 81 \% \sim 89 \%$ ee $\mathrm{R}^{\prime}=i-\mathrm{Pr}$, cyclo- $\mathrm{C}_{6} \mathrm{H}_{11}$, cyclo- $\mathrm{C}_{5} \mathrm{H}_{9}$, yield: $84 \% \sim 91 \%, 92 \% \sim 94 \%$ ee

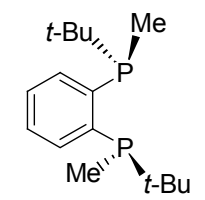

$(R, R)-B^{*} \mathrm{P}^{*}(\mathbf{3 5})$

\section{4 手性单齿磷配体}

与双磷配体相比，手性单磷配体具有制备简单、成 本低廉等优点, 2000 年以来在过渡金属催化的不对称反 应中取得了巨大成功 ${ }^{[39]}$. 尽管如此, 在烯烃的不对称氢 甲酰化反应中, 关于使用手性单磷配体的报道仍相对较 少，而且大多选择性控制一般不高 ${ }^{[40]}$. 2004 年, Ojima

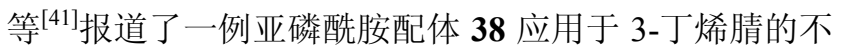
对称氢甲酰化反应, 在优化的反应条件下, 取得了 96 ： 4 的异正比和 $80 \% e e$ 值(Eq. 13). 虽然该结果表明手性 单膦配体可以在铑催化烯烃的不对称氢甲酰化反应中 取得良好的区域和对映选择性，但至今在不对称氢甲酰 化反应中还没有发现底物应用范围广泛的单膦配体. 因 此, 在不对称氢甲酰化反应中, 发展活性高、选择性好 的手性单磷配体仍然是一个挑战性课题.

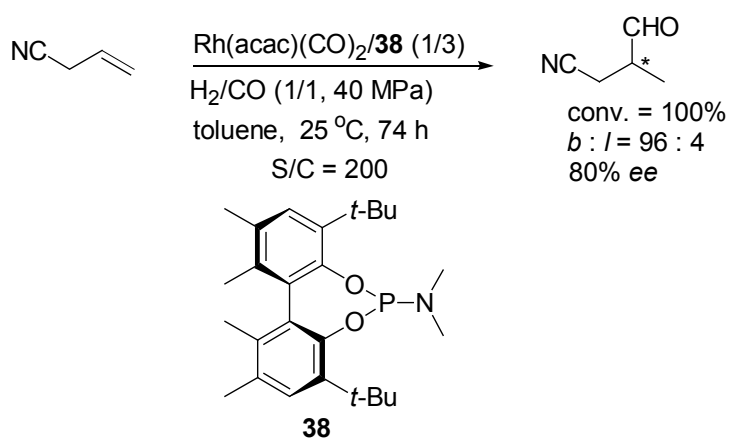

\section{5 超分子手性膦配体}

近年来, 随着超分子化学的发展, 基于分子间作用
组装构建膦配体的策略引起人们的重视. 与传统的共价 键连接的膦配体相比，超分子膦配体基于分子间氢键或 配位键等相对较弱的作用构筑膦配体，由于非共价相互 作用的可逆性和选择性，使得超分子膦配体具有合成简 便和组合灵活等优点, 在烯烃不对称催化氢化等反应中 取得了一些成功应用 ${ }^{[42]}$. 在氢甲酰化研究中, 2006 年 Reek 等 ${ }^{[43]}$ 以刚性的 bis-Zn(II)-salphen 为模板, 通过两种 不同单膦配体上的吡啶单元分别与 $\mathrm{Zn}(\mathrm{II})$ 的配位作用, 将手性单齿亚磷酸酯和三芳基磷组合，在 $\mathrm{Rh}(\mathrm{I})$ 前体和 $\mathrm{H}_{2} / \mathrm{CO}$ 存在下选择性地形成了单一的组装体催化剂 39 (Eq. 14). 该超分子组装的铑催化体系在苯乙烯的不对 称氢甲酰化反应中, 可以良好的区域选择性 $(b: l=$ $9.2 ： 1)$ 和对映选择性 $(72 \% e e)$ 得到相应的支链醛.

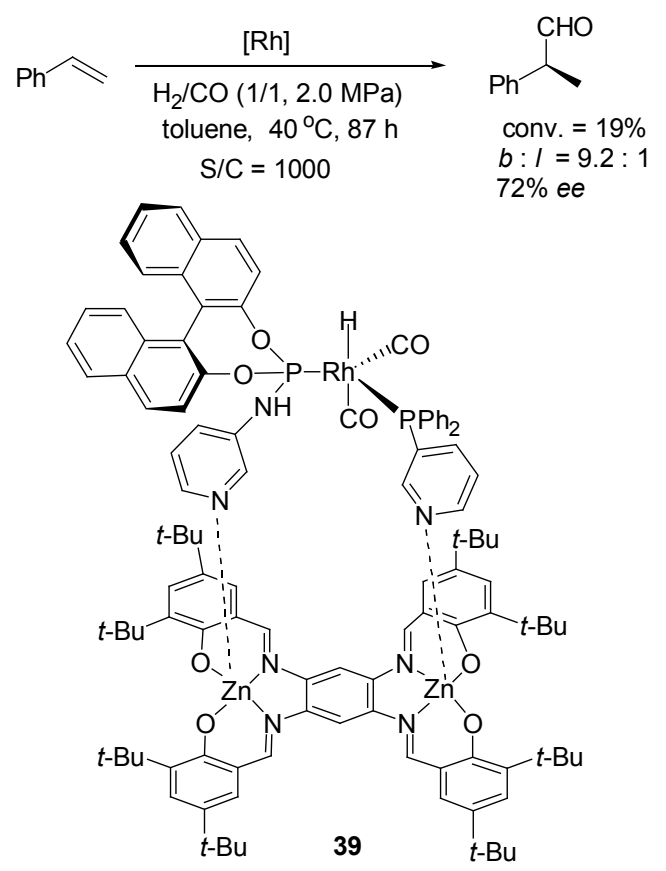

2012 年, Reek 等 ${ }^{[44]}$ 通过反应体系中手性双膦配体 上的吡啶基团与 $\mathrm{Ru}$-卟啉配位作用, 现场形成 $\mathrm{Ru}$-卟啉 修饰的超分子手性配体 40, 与铑组成的催化剂在一些 芳基乙烯底物的不对称氢甲酰化反应(Eq. 15)中，区域 选择性异正比最高达 9.2, 支链醛的 ee 值最高可达 $82 \%$. Reek 等 ${ }^{[45]}$ 还以 bis-Zn(II)-salphen 为模板，通过两个手性 单齿亚磷酰胺配体上的吡啶单元分别与 $\mathrm{Zn}(\mathrm{II})$ 的配位作 用形成模板配体组合成为一类新的双齿手性配体 41 (Eq. 16). 该催化剂体系在非官能团的 2-辛烯的不对称 氢甲酰化反应中，表现出了中等的区域选择性和良好的 对映选择性, ee 值最高可达 $86 \%$.

基于组装理念构建手性超分子磷配体在某些烯烃 的不对称氢甲酰化反应中取得了一些初步的进展，但目 前文献报道的催化剂类型仍十分有限，其合成和表征也 略显繁琐. 另外，由于组装过程利用分子间相对较弱的 


$$
\underset{\mathrm{Ar} \curvearrowright}{\stackrel{\mathrm{Rh}(\mathrm{acac})(\mathrm{CO})_{2} / 40(1 / 3)}{\mathrm{H}_{2} / \mathrm{CO}(1 / 1,2.0 \mathrm{MPa})}} \begin{aligned}
& \text { toluene, } 25^{\circ} \mathrm{C}, 84 \mathrm{~h} \\
& \mathrm{~S} / \mathrm{C}=200
\end{aligned} \quad \begin{aligned}
& \text { conv. }=9 \% \sim 16 \% \\
& b: / \text { up to } 99: 1 \\
& \text { ee up to } 82 \%
\end{aligned}
$$
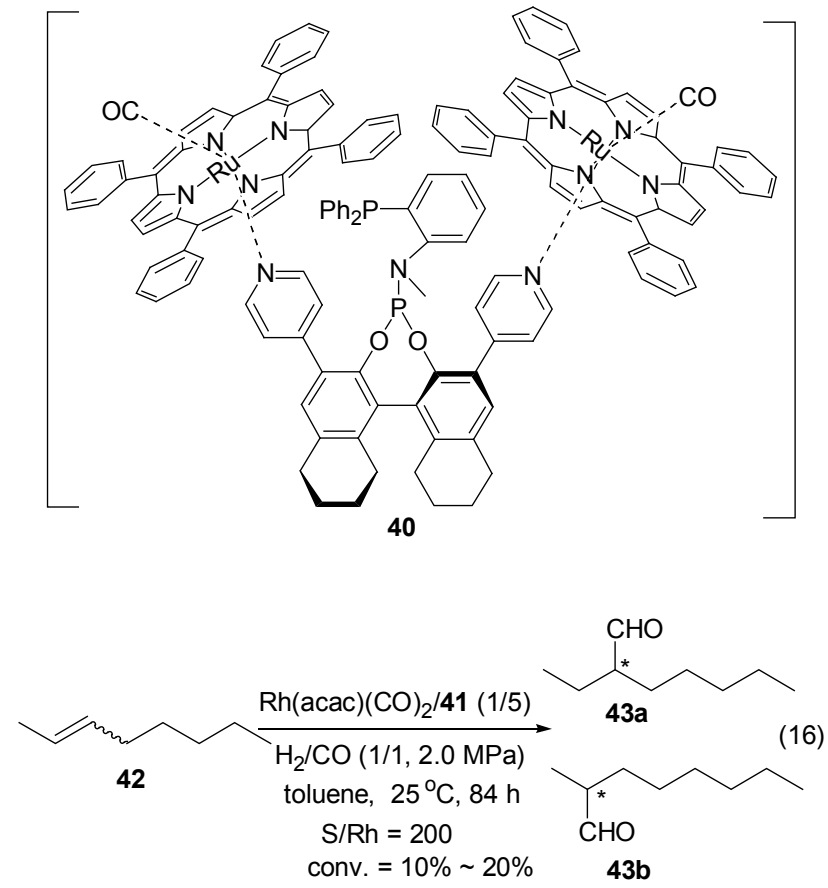

42a: 反式烯烃, $43 a / 43 b=40 / 60,43 a: 72 \% e e$ 42b: 顺式烯烃， 43a/43b = 30/70, 43a: 86\% ee

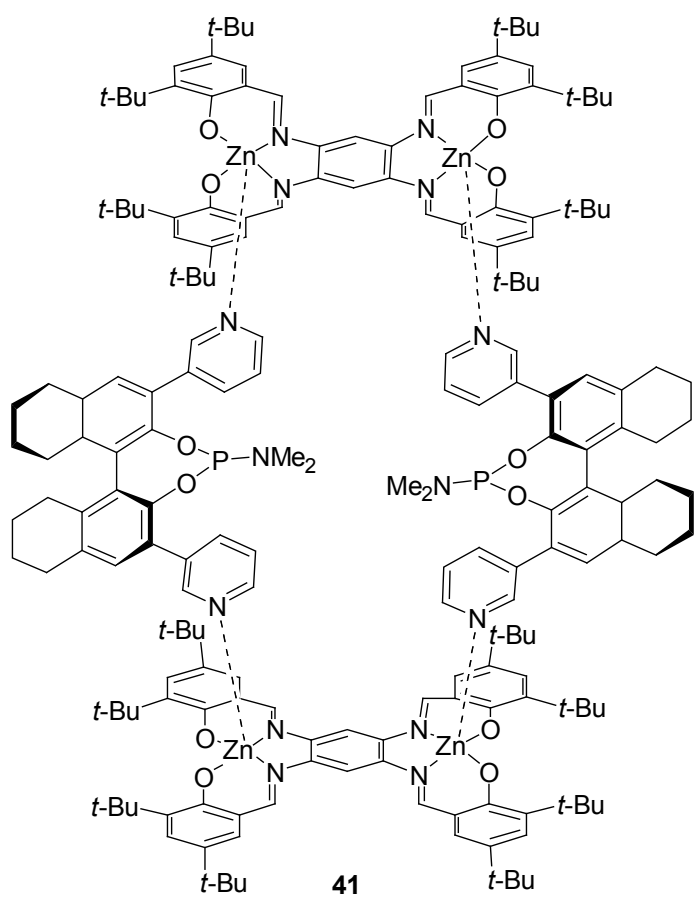

非共价键作用的特点, 催化反应通常需在较低温度下进 行, 导致配体的用量较大且反应时间较长, 这在一定程 度上限制了超分子磷配体在铑催化氢甲酰化反应中的
应用。

\section{6 手性辅基导向的不对称氢甲酰化反应}

通过底物上含磷手性辅基对 $\mathrm{Rh}$ 催化剂的导向作用 来控制区域选择性和对映选择性，是近来出现的不对称 氢甲酰化反应的一条途径. 2004 年, Breit 等 ${ }^{[46]}$ 通过预先 将手性二茂铁骨架的磷配体 $\left(S_{\mathrm{p}}\right)-O-\mathrm{DPPF}$ 经过酰基引入 底物形成光学活性的化合物 44, 利用手性辅基的膦对 催化剂的导向作用, 实现了 44 不对称氢甲酰化的区域 和立体选择性控制(Eq. 17). 通过该手性辅基的方法虽 然可以取得到光学纯度很高的产物 $(>99 \% e e)$, 但是反 应过程中需要增加引入和脱除手性磷辅基的步骤, 并且 反应中需要使用等物质的量的手性磷试剂，增大了反应 成本.

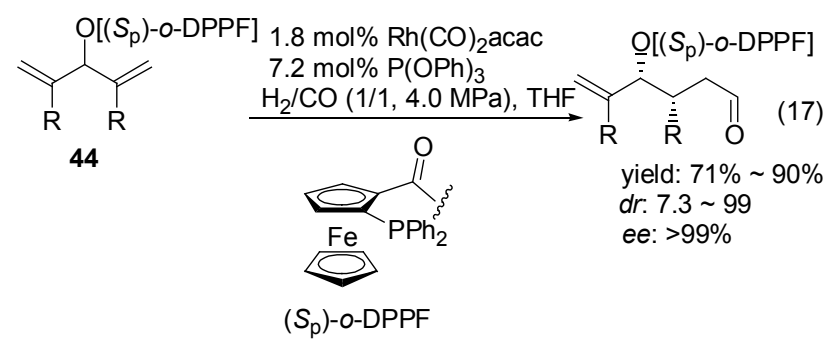

2010 年, Tan 等 ${ }^{[47]}$ 发展了一类新的手性单磷配体 $\mathbf{4 5}$, 并将其作为手性辅基前体应用于 1,2-双取代烯烃 PMP保护的烯丙基胺 47 的不对称氢甲酰化反应中(Scheme 9). 在酸性反应条件下，体系中的配体 $\mathbf{4 5}$ 与烯丙基胺 $\mathbf{4 7}$ 通过 $\mathrm{N}, \mathrm{O}$ 交换反应, 可逆地形成在底物上连接手性含 磷辅基的中间体 46, 后者在 $\mathrm{Rh}$ 催化下发生不对称氢甲 酰化反应，所得到的醛通过嗍氢化钠还原，即以中等到 良好的收率和优良的对映选择性(73\% 93\% ee) 得到手 性醇 48. 与 Eq. 17 的方法相比较, 该反应通过配体 45 与底物 47 的可逆反应引入手性辅基, 因此只需使用催 化量的配体.

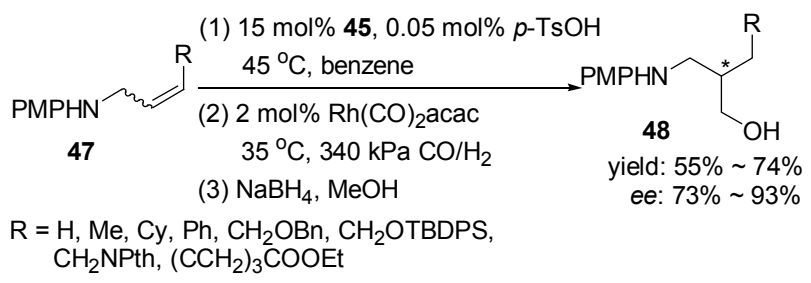

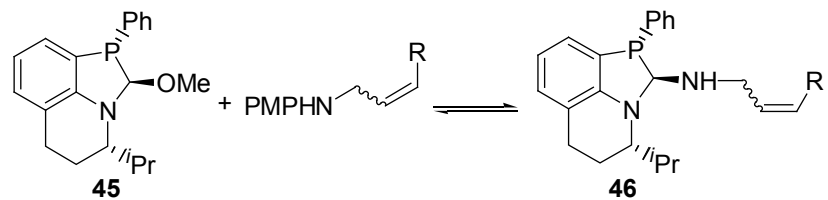

Scheme 9 
通过底物分子上配位辅基导向的不对称氢甲酰化 对于特定官能团化的烯烃底物可以取得较高的对映选 择性, 但是该方法还存在底物类型的限制以及配体用量 通常较大等缺陷. 烯烃底物一般需含有羟基或者胺基官 能团以便于手性磷辅基的加载, 另外, 氢甲酰化反应完 成后辅基的脱除也增加了反应步骤.

\section{7 结束语}

在过去的 20 年中, 铑催化烯烃不对称氢甲酰化反 应的研究取得了显著的进展, 发展了多种类型的手性膦 配体，其中一些配体在多种类型烯烃底物中的氢甲酰化 反应中表现出较高的活性和选择性. 其中杂合双膦配体 $(R, S)$-BINAPHOS 及双-3,4-二氮磷杂环伐烷配体 $(S, S, S)$ Bisdiazaphos 尤为引人关注, 无论从底物类型的适应性、 催化活性、化学、区域和对映选择性等多个方面, 其性 能都是十分突出的, 并已在一些较复杂烯烃底物的不对 称氢甲酰化反应中取得了成功应用. 虽然如此, 相比于 其它发展较为成熟的不对称催化反应如氢化反应而言, 不对称氢甲酰化反应的研究领域还存在许多亟待解决 的问题. 目前不对称氢甲酰化反应研究的烯烃底物类型 较少, 且主要集中在芳基乙烯、醋酸乙烯酯和 3-丁烯腈 等少量几种单取代烯烃上，因此有必要进一步拓展烯烃 底物的种类. 另外, 迄今为止在该反应中有广泛底物通 用性的优势配体仍屈指可数, 因此发展新的手性配体, 以及相关的反应性研究仍将是今后不对称氢甲酰化反 应研究的一个主要方向. 从合成应用方面考虑, 铑催化 的烯烃不对称氢甲酰化在药物及天然产物的合成实例 还不多见，凸显出该反应中尚还缺少优势催化剂的困 难. 总之, 在铑催化烯烃不对称氢甲酰化研究中, 新配 体的开发仍是一个具有挑战性和发展潜力的方向, 在实 际合成应用方面有着广阔的拓展空间.

\section{References}

[1] (a) Claver, C.; van Leeuwen, P. W. N. M. Rhodium Catalyzed Hydroformylation, Kluwer Academic Publishers, Dordrecht, 2002.

(b) Franke, R.; Selent, D.; Börner, A. Chem. Rev. 2012, 112, 5675.

(c) Su, K.; Jiang, H.; Zhu, D.; Fu, H.; Zheng, X.; Yuan, M.; Li, R.; Chen, H. Acta Chim. Sinica, 2013, 71, 844.

[2] Naqvi, S. Oxo Alcohols. Process Economics Program Report 21E, SRI Consulting, Menlo Park, CA, 2010.

[3] (a) Agbossou, F.; Carpentier, J. F.; Mortreaux, A. Chem. Rev. 1995, 95, 2485.

(b) Gual, A.; Godard, C.; Castillón, S.; Claver, C. Tetrahedron: Asymmetry 2010, 21, 1135.

[4] Botteghi, C.; Paganelli, S.; Schionato, A.; Marchetti, M. Chirality 1991, 3, 355.

[5] Botteghi, C.; Consiglio, G.; Pino, P. Chimia 1972, 26, 141.

[6] (a) Ogata, I.; Ikeda, Y. Chem. Lett. 1972, 487.

(b) Tanaka, M.; Watanabe, Y.; Mitsudo, T.-A,; Yamamoto, K.; Takeeami, Y. Chem. Lett. 1972, 483.
[7] Salomon, C.; Consiglio, G.; Botteghi, C.; Pino, P. Chimia 1973, 27, 215.

[8] Stille, J. K.; Su, H.; Brechot, P.; Parrinello, G.; Hegedus, L. S. Organometallics 1991, 10, 1183.

[9] (a) Sakai, N.; Mano, S.; Nozaki, K.; Takaya, H. J. Am. Chem. Soc. 1993, 115,7033

(b) Nozaki, K.; Nanno, T.; Takaya, H. J. Organomet. Chem. 1997, 527, 103.

(c) Lambers-Verstappen, M. M. H.; de Vries, J. G. Adv. Synth. Catal. 2003, 345, 478

[10] (a) Saskai, N.; Nozaki, K.; Takaya, H. J. Chem. Soc., Chem. Commun. 1994, 395.

(b) Nozaki, K.; Sakai, N.; Nanno, T.; Higashijima, T.; Mano, S.; Horiuchi, T.; Takaya, H. J. Am. Chem. Soc. 1997, 119, 4413.

(c) Nozaki, K.; Takaya, H.; Hiyama, T. Top. Catal. 1997, 4, 175.

[11] Hoiuchi, T.; Ota, T.; Shirakawa, E.; Nozaki, K.; Takaya, H. J. Org. Chem. 1997, 62, 4285.

[12] Mazuela, J.; Coll, M.; Pàmies, O.; Diéguez, M. J. Org. Chem. 2009, 74,5440 .

[13] Tanaka, R.; Nakano, K.; Nozaki, K. J. Org. Chem. 2007, 72, 8671

[14] Liu, P.; Jacobsen, E. N. J. Am. Chem. Soc. 2001, 123, 10772.

[15] (a) Yan, Y.; Zhang, X. J. Am. Chem. Soc. 2006, 128, 7198.

(b) Zhang, X.; Cao, B.; Yan, Y.; Yu, S.; Ji, B.; Zhang, X. Chem. Eur. J. 2010, 16,871 .

[16] Zhang, X.; Cao, B.; Yu, S.; Zhang, X. Angew. Chem., Int. Ed. 2010, 49, 4047.

[17] Chikkali, S. H.; Bellini, R.; de Bruin, B.; van der Vlugt, J. I.; Reek, J. N. H. J. Am. Chem. Soc. 2012, 134, 6607.

[18] Noonan, G. M.; Fuentes, J. A.; Cobley, C. J.; Clarke, M. L. Angew. Chem., Int. Ed. 2012, 51, 2477.

[19] (a) Babin, J. E.; Whiteker, G. T. US 5360938, 1993 [Chem. Abstr. 1995, 122, 186609].

(b) Buisman, G. J. H.; Vos, E. J.; Kamer, P. C. J.; Van Leeuwen, P. W. N. M. J. Chem. Soc., Dalton Trans. 1995, 409.

[20] Clark, T. P.; Landis, C. R.; Freed, S. L.; Klosin, J.; Abboud, K. A. J. Am. Chem. Soc. 2005, 127, 5040.

[21] Diéguez, M.; Pàmies, O.; Ruiz, A.; Castillón, S.; Claver, C. Chem. Eur. J. 2001, 7, 3086

[22] (a) Diéguez, M.; Pàmies, O.; Claver, C. Chem. Commun. 2005, 1221.

(b) Gual, A.; Godard, C.; Castillón, S.; Claver, C. Adv. Synth. Catal. 2010, 352, 463.

[23] (a) Cobley, C. J.; Klosin, J.; Qin, C.; Whiteker, G. T. Org. Lett. 2004, 6, 3277.

(b) Cobley, C. J.; Gardner, K.; Klosin, J.; Praquin, C.; Hill, C.; Whiteker, G. T.; Zanotti-Gerosa, A. J. Org. Chem. 2004, 69, 4031.

[24] Zhao, B.; Peng, X.; Wang, W.; Xia, C.; Ding, K. Chem. Eur. J. 2008, 14, 7847.

[25] Peng, X.; Wang, Z.; Xia, C.; Ding, K. Tetrahedron Lett. 2008, 49, 4862.

[26] Breeden, S.; Cole-Hamilton, D. J.; Foster, D. F.; Schwarz, G. J.; Wills, M. Angew. Chem., Int. Ed. 2000, 39, 4106.

[27] (a) Jiang, Y.; Xue, S.; Li, Z.; Deng, J.; Mi, A.; Chan, A. S. C. Tetrahedron: Asymmetry 1998, 9, 3185.

(b) Jiang, Y.; Xue, S.; Yu, K.; Li, Z.; Deng, J.; Mi, A.; Chan, A. S. C. J. Organomet. Chem. 1999, 586, 159.

(c) Yan, M.; Li, X.-S.; Chan, A. S. C. Chin. J. Chem. 2004, 22, 203.

[28] (a) Klosin, J.; Landis, C. R. Acc. Chem. Res. 2007, 40, 1251.

(b) Thomas, P. J.; Axtell, A. T.; Klosin, J.; Peng, W.; Rand, C. R.; Clark, T. P.; Landis, C. R.; Abboud, K. A. Org. Lett. 2007, 9, 2665.

[29] McDonald, R. I.; Wong, G. W.; Neupane, R. P.; Stahl, S. S.; Landis, C. R. J. Am. Chem. Soc. 2010, 132, 14027. 
[30] Watkins, A. L.; Hashiguchi, B. G.; Landis, C. L. Org. Lett. 2008, $10,4553$.

[31] Clemens, A. J. L.; Burke, S. D. J. Org. Chem. 2012, 77, 2983.

[32] Risi, R. M.; Burke, S. D. Org. Lett. 2012, 14, 1180.

[33] Axtell, A. T.; Cobley, C. J.; Klosin, J.; Whiteker, G. T.; ZanottiGerosa, A.; Abboud, K. A. Angew. Chem., Int. Ed. 2005, 44, 5834.

[34] Zhang, Z.; Qian, H.; Longmire, J.; Zhang, X. J. Org. Chem. 2000, $65,6223$.

[35] Sherill, W. M.; Rubin, M. J. Am. Chem. Soc. 2008, 130, 13804.

[36] Tamura, K.; Sugiya, M.; Yoshida, K.; Yanagisawa, K.; Imamoto, T. Org. Lett. 2010, 12, 4400.

[37] (a) Wang, X.; Buchwald, S. L. J. Am. Chem. Soc. 2011, 133, 19080. (b) Uhlemann, M.; Börner, A. Chem CatChem 2012, 4, 753.

[38] (a) Keuelemans, A. I. M.; Kwantes, A.; van Bavel, T. Recl. Trav. Chim. Pays-Bas 1948, 67, 298.

(b) Clarke, M. L.; Roff, G. J. Chem.-Eur. J. 2006, 12, 7978.

[39] (a) Tang, W.; Zhang, X. Chem. Rev. 2003, 103, 3029.

(b) Xie, J.-H.; Zhu, S.-F.; Zhou, Q.-L. Chem. Rev. 2011, 111, 1713.

(c) Wang, D.-S.; Chen, Q.-A.; Lu, S.-M.; Zhou, Y.-G. Chem. Rev. 2012, 112, 2557.

(d) Guo, H.; Ding, K.; Dai, L. Chin. Sci. Bull. 2004, 49, 1575 (in Chinese).

(郭红超, 丁奎岭, 戴立信, 科学通报, 2004, 49, 1575.)

(e) Xie, J.-H.; Zhu, S.-F.; Zhou, Q.-L. Acta Chim. Sinica 2012, 70,
1427.

(f) Liu, Y.; Wang, Z.; Ding, K. Acta Chim. Sinica 2012, 70, 1427.

[40] (a) Mazuela, J.; Pàmies, O.; Diéguez, M.; Palais, L.; Rosset, S.; Alexakis, A. Tetrahedron: Asymmetry 2010, 21,2153.

(b) Carrilho, R. M. B.; Neves, A. C. B.; Lourenco, M. A. O.; Abreu, A. R.; Rosado, M. T. S.; Abreu, P. E.; Eusébio, M. E. S.; Kollár, L.; Bayón, J. C.; Pereira, M. M. J. Organomet. Chem. 2012, 698, 28. (c) Fan, B.-M.; Xie, J.-H.; Zhou, Z.-T.; Zang, Q.; Tu, Y.-Q.; Zhou, Q.-L. Chem. J. Chin. Univ. 2006, 27, 1984 (in Chinese). (樊保敏, 谢建华, 周章涛, 张齐, 涂永强, 周其林, 高等学校化 学学报, 2006, 27, 1984.)

[41] Hua, Z.; Vassar, V. C.; Choi, H.; Ojima, I. Proc. Natl. Acad. Sci. U. S. A. 2004, 101, 5411.

[42] Li, Y.; Wang, Z.; He, Y.; Fan, Q. Chin. J. Org. Chem. 2010, 30, 338 (in Chinese).

(李永, 王志玲, 何艳梅, 范青华, 有机化学, 2010, 30, 338.)

[43] Kuil, M.; Goudriaan, P. E.; van Leeuwen, P. W. N. M.; Reek, J. N. H. Chem. Commun. 2006, 4679.

[44] Bellini, R.; Reek, J. N. H. Chem. Eur. J. 2012, 18, 13510.

[45] Gadzikwa, T.; Bellini, R.; Dekker, H. L.; Reek, J. N. H. J. Am. Chem. Soc. 2012, 134, 2860.

[46] Breit, B.; Breuninger, D. J. Am. Chem. Soc. 2004, 126, 10244.

[47] Worthy, A. D.; Joe, C. L.; Lightburn, T. E.; Tan, K. L. J. Am. Chem. Soc. 2010, 132, 14757. 